\title{
Sociocultural Context for Sex Differences in Addiction
}

by

Jill B. Becker ${ }^{1}$, Michelle McClellan ${ }^{2}$, and Beth Glover Reed ${ }^{3}$

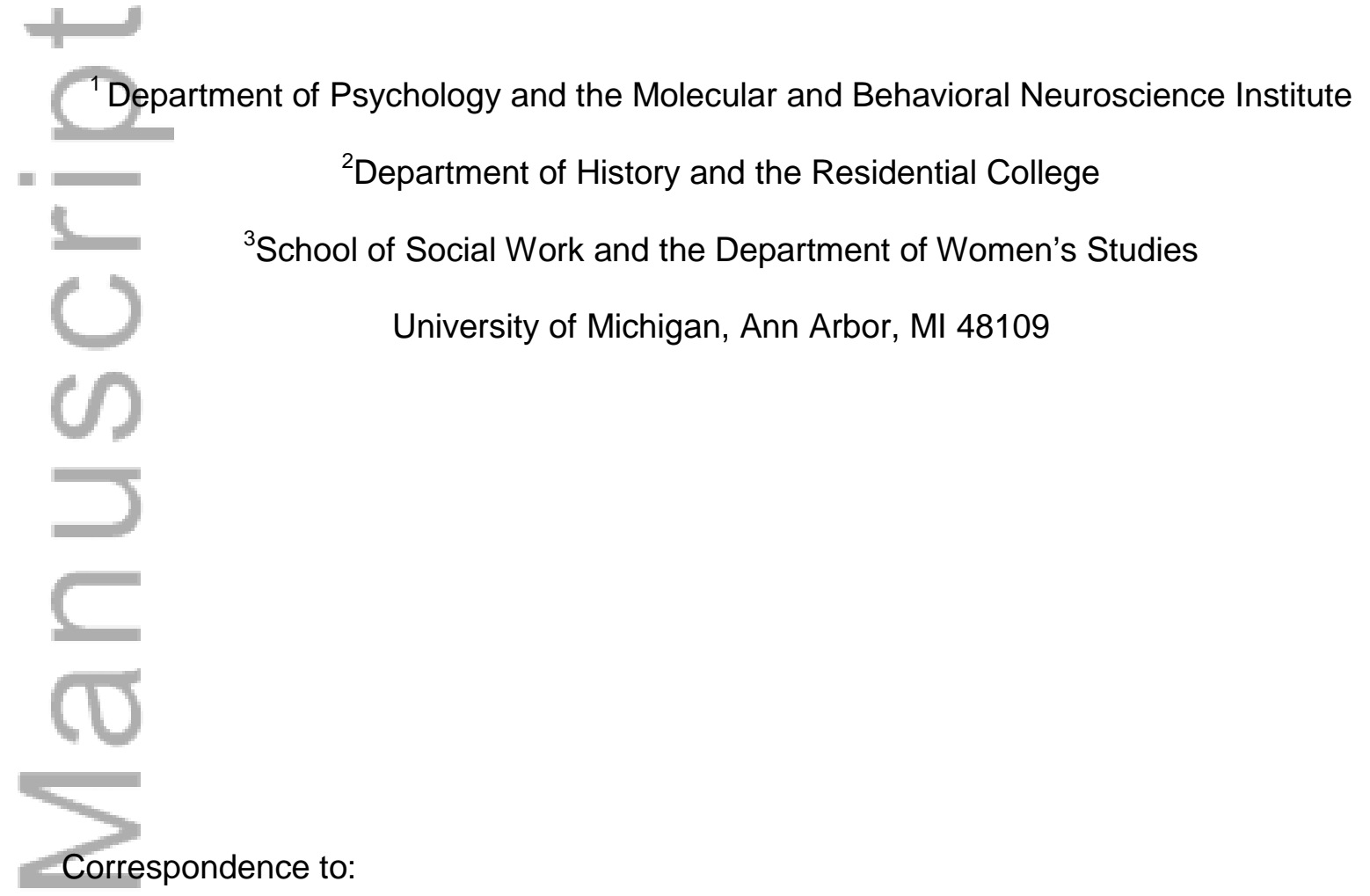

Jill B. Becker

(

University of Michigan

205 Zina Pitcher Place

Ann Arbor, MI 48109

-jbbecker@umich.edu

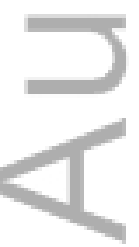

This is the author manuscript accepted for publication and has undergone full peer review but has not been through the copyediting, typesetting, pagination and proofreading process, which may lead to differences between this version and the Version of Record. Please cite this article as doi: $10.1111 / \mathrm{adb} .12383$

This article is protected by copyright. All rights reserved. 


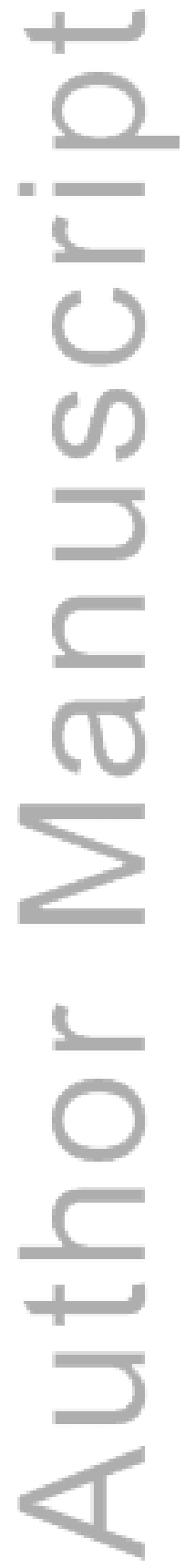

This article is protected by copyright. All rights reserved. 


\section{ABSTRACT}

In this review we discuss the importance of investigating both sex and gender differences in addiction and relapse in studies of humans and in animal models. Addiction is both a cultural and biological phenomenon. Sex and gender differences are not solely determined by our biology, nor are they entirely cultural; they are interactions between biology and the environment that are continuously played out throughout development. Lessons from the historical record illustrate how context and attitudes affect the way that substance use in men and women is regarded. Finally, cultural and environmental influences may differentially affect men and women, and affect how they respond to drugs of abuse and to treatment protocols. We recommend that both animal models and clinical research need to be developed to consider how contextual and social factors may influence the biological processes of addiction and relapse differentially in males and females.

KEY WORDS: Animal Models, Cultural Influences, Gender Differences, Sex Differences

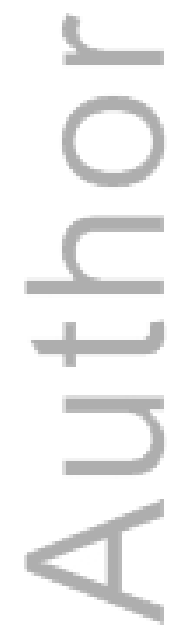

This article is protected by copyright. All rights reserved. 


\section{Introduction}

As described in the opening commentary and other articles in this special issue, many factors can contribute to sex differences in addiction. We are at an important juncture for the inclusion of sex/gender differences in the advancement of the understanding of the biology of addiction in both sexes. Addiction, like other complex behaviors, results from the complicated interplay between an individual and his or her environment. Biology and experience, as well as the interactions between them, differ by sex (as we currently study laboratory animals) and by sex and gender (in the case of humans who live in a more nuanced and variable environment).

We define gender as a socio-cultural process that shapes concepts of feminine and masculine attributes that may be consistent with the biological sex of an individual (i.e., cisgender), but for some individuals may not be consistent with the biological sex (i.e., transgender). While some may argue that laboratory animals can also have gender, current practices do not allow such attributes to be expressed or measured. When both sex and gender are involved we will use sex/gender. Studies most often discuss both sex and gender as binaries, and make heterosexual and cisgender assumptions.

It will be important in future research about both sex and gender to consider both as continua or clusters of overlapping factors. For the purposes of the discussion here we acknowledge a cisgender/heterosexual perspective, as most data we will discuss have this perspective. As we investigate the multifaceted phenomenon that is addiction, 
sex/gender differences must be included as important variables in our research designs so as to more accurately evaluate the roles these factors play in addiction and recovery and to better appreciate the dynamic relationship between individuals and their environments.

For decades, the scientific community has avoided the study of females and/or argued that sex differences are not important. Cahill argues that the main reason sex differences have not been investigated thoroughly is that scientists want to believe that men and women, and by extrapolation male and female animals, are essentially the same (other than the technicality of reproduction and regulation of the reproductive hormones) (Cahill, 2014). From this logic, Cahill argues, many scientists infer that those biological components that males and females share are the fundamental processes of importance to all organisms, and the differences between the sexes are unimportant nuances or technicalities, primarily related to reproduction. The scientific community has implicitly inferred that sex and gender differences are not important for our understanding of the biology or neurobiology of other aspects of the organism. We now know that many sex and gender differences are of fundamental importance for our understanding of many biological processes including addiction and it is time to apply this knowledge to our scientific investigations.

The Culture of Gender. Within cultural contexts, every society has expectations associated with gender. Male and female are often understood as two separate conditions that differ substantially from each other, with little overlap. In fact, in many cultures, the two sexes are perceived to be "opposites", thus the term "opposite sex" is associated with dichotomous characteristics (e.g., if men are tough and stoic, women are soft and emotional). Most people

This article is protected by copyright. All rights reserved. 
can list adjectives commonly associated with each gender, and usually two thirds of them are considered opposites of each other. In addition to oversimplifying the world, the belief that male and female are dichotomous and biologically determined has been used to justify exclusion and unequal status in the U.S. and many other societies. Adjectives associated with male and female are not only dichotomous, but those associated with men are also more valued, with 60 per cent or more associated with leadership, strength, and other socially valued conditions, reinforcing the inferior social position of girls and women (Bem, 1994; Lorber, 1994)

Biological explanations of sex differences have been used in the past to disenfranchise women, offered as justification for their exclusion from such realms as higher education, politics, business, and sports, just to name a few (Clark, 1990; Degler, 1991; Kevles, 1985). Even today, misinterpretations of data on sex differences in brain and cognitive function are used as excuses to explain disparities which actually have many causes, such as why there are fewer women in science, technology, engineering and mathematics (STEM) disciplines (Petersen and Hyde, 2014).

For these reasons, in the late 1960's and early 70's, activists and scholars began to make distinctions between sex and gender, with sex referring to complex biological elements, and gender defined as sets of social, cultural and behavioral prescriptions, often used to explain constrained roles and opportunities (Fausto-Sterling, 2012; Lorber, 2005). Separating sex from gender conceptually allowed scholars to focus on the sociocultural forces that shape how gender is understood and enacted, and to critique simplistic biological justifications about the fundamental "nature" of women and men. Data about biological sex differences are often deeply distrusted, and this distrust is complicated by complex scientific terminologies and research

This article is protected by copyright. All rights reserved. 
methods that are not well-understood, and that do not incorporate attention to basic sociocultural and relational phenomena that are very important in human societies.

Influenced by these contexts there has been a backlash from the popular media against scientists who investigate sex differences in the brains of men and women. Terms such as "neurosexism" have been coined to characterize this field of inquiry (Fine, 2013). This reflects the anger and suspicion that scientific findings will be used to justify unequal treatment for women, as has happened in the past.

Today's scientists are not the first generation to grapple with concerns about biological determinism or navigate cultural debates about how men and women should behave. In particular, as will be discussed below in more detail, scientists need to emphasize the plasticity of the brain and combat terms like "hard-wired" that are frequently used in popular discourse to characterize sex differences. An historical perspective can help us appreciate what is at stake in presenting our findings to the public. Taking a longer view can also demonstrate the importance of environment, stigma, and how factors such as the accessibility of drugs and social sanctions attached to their use, influenced rates of addiction and its manifestations in women and men. Finally, we need to be aware of how our findings are perceived by scientists from other disciplines and the public.

Sex, Gender and Addiction. What does it mean to be male or female? Our very existence is shaped by the cultural categories of 'male' and 'female'. The first thing we learn about a newborn baby is "It's a boy!" or "It's a girl!" How we treat the developing fetus, the newborn baby, the toddler, the preteen, the adolescent and the adult are all shaped by our belief that sex / gender is a fundamental and unchanging characteristic of each of us. Whether it's a boy or a girl matters to us. It defines our interactions with others.

This article is protected by copyright. All rights reserved. 
The processes mediating the transformation from fertilized ovum to a baby boy or girl are not all genetically derived. After the first step of sexual determination, the rest of what happens is driven primarily by hormones produced by the fetal testes (or absence of testes), and these processes can be influenced by the fetal environment (e.g., whether or not the mom is well nourished, healthy and free from undue stress). A complete discussion of the processes can be found in the article by Sanchis-Segura and Becker (this issue) and so we will not repeat those details here. As a consequence of these processes, most baby mammals become either masculine or feminine in their outward appearance and usually their internal sex organs correspond to their outward appearance.

The bodies of men and women have many elements that look and function in the same basic way (e.g., we all have arms and legs, lungs and a liver, etc.). Just like our bodies, the brain has regions that look and function the same in men and women and other areas that look and function differently. These differences are not absolute, nor are they uniform or consistent across the population. For example, a given male or female may have small, sensitive hands while having a muscular physique, even though in general across the population more women have small hands and more men have a muscular physique. Similarly, while there are sex differences in the brain, it is not necessarily the case that all areas of a given brain are "masculine" (displaying characteristics more likely to be seen in males) or "feminine" (with features more strongly associated with females). In fact, the human brain tends to be a mosaic of sexullly differentiated brain regions, some of which tend to be more "masculine", and others more "feminine" (Joel et al., 2015).

Not only do our brains differ in terms of how "masculine" or "feminine" each region may be, the plasticity of the brain means that it develops in very complex and dynamic ways. The 
findings of Joel and colleagues (Joel et al., 2015) suggest that brains do not become masculine or feminine through one process or a linear series of processes. Rather, the brains of women and men develop, as our bodies do, through complex interactions among the biology (the brain developing in response to genetic and hormonal signals), the physical environment, and sociocultural experiences of an individual, all of which shape the development of the brain throughout life.

It is likely that this complexity in how the brain develops, with biological processes unfolding in a complicated social environment, helps explain observed sex/gender differences in addiction. Those who study addiction in humans and in animal models as well as clinicians who work with addicted men and women have noted that there are sex/gender differences in aspects of the development of addiction and in the recovery process (Becker and Koob, 2015). At least some of these sex differences can be demonstrated to be mediated by biological differences in the brains of males and females in animal models. These differences have been reviewed extensively, so they will be briefly summarized here.

The most striking sex difference in addiction is that those women who are vulnerable for addiction progress through the landmark stages from initial use to dependence at a faster rate than men do for all drugs of abuse (Becker and Koob, 2015; Brady and Randall, 1999). There are other differences as well: women who are heavy drinkers are more sensitive to the effects of stress and interpersonal problems on craving for alcohol and relapse than are men, while men are möre sensitive to drug-associated cues (Hartwell and Ray, 2013; Walitzer and Dearing, 2006). Additionally, trauma history and current trauma-related symptoms are significantly associated with relapse in women, but not men (Heffner et al., 2011; Hyman et al., 2008; Kachadourian et al., 2014).

This article is protected by copyright. All rights reserved. 
Rats also exhibit similar sex differences in addiction. Female rats acquire drug taking more rapidly than males, progress to addictive-like behavior more rapidly and will work harder than male rats, by pressing a lever or nose poking sometimes over 1000 times to get a single dose of cocaine (Becker and Hu, 2008; Becker et al., 2012) Females rats also show greater stress-induced reinstatement of responding for drug than do males, but less cue-induced reinstatement (Anker and Carroll, 2010). These findings demonstrate that there are fundamental biological differences that impact males and females differently when drugs of abuse are taken. The strong evidence seen in male and female rodents that parallels the human condition suggests that similar neural mechanisms, in addition to cultural differences, could be a factor influencing the sex / gender differences in addiction seen in men and women.

Biological Determinism vs. Scientific Findings. For the general public, as well as some scholars from other fields, declaring that there are sex differences means to them that male and female brains are "hard-wired" to be different from each other. The current dominance of the model of addiction as a "brain disease" also contributes to the belief that our brains are "wired" in certain ways and that it is almost impossible to change them. In other words, when a scientist explains there are sex differences in the brain that result in women becoming addicted more rapidly, many non-scientists assume that there is nothing anyone can do to change this. Biological explanations become overly simplified, as the general public concludes that "the behavior is different because the brains of men and women are different, so it was inevitable that those women would be addicts and that cannot ever be changed".

Most neuroscientists are surprised by this interpretation of sex differences in the brain and by societal attitudes in this regard. As scientists, we understand that each human's brain is not "hardwired" from conception or birth, but rather is the result of an intricate interplay between 
biology and environment across the life span. If the fetal gonads become testes the hormones released will act in the brain to induce sex-specific changes at critical times during development. These biological sex differences interact with their surroundings to produce sex- and genderrelated behaviors appropriate to the individual and the world in which she or he lives. Since the brain shapes all behaviors, and experience in turn can shape the brain, a neuroscientist will conclude that men and women have different brains as a result of their experiences interacting with their biology. The complexity of these ideas is lost in translation to the general public when scientific findings are applied simplistically yet persuasively in political and cultural settings without adequate explanation.

These different perspectives and frames of reference can lead to considerable confusion for scientists and the lay public, both of whom ask whether the sex differences in the brain are "fundamental" or just nuances that don't really matter. In other words, it can be difficult to evaluate the importance of sex differences even when they are identified.

Part of the reason for the confusion is that there are multiple forms of sex differences in the brain that tend to be conflated. As discussed by Sanchis-Segura and Becker (SanchisSegura and Becker, 2016) and McCarthy (McCarthy et al., 2012) there are four types of sex differences that we will operationally define as:

1) Qualitative Differences. The most extreme form of sex difference is exemplified by reproductive functions and behavior where there are two forms that are either primarily male or female (only one can be expressed at a time; in other words, these forms cannot be measured with the same metric. 
2) Quantitative Differences. There are sex differences where males and females differ in their mean, variance or both, but the trait is same in both sexes and can be measured on the same scale in both sexes.

3) Convergent Differences. There are also sex differences where the behavior or functional endpoint is the same in males and females but the neural underpinnings are different (i.e., convergence of function while the mechanisms mediating the trait are different) or instances where males and females most frequently exhibit the same behavior in a given situation, but may exhibit a sex differences due to different physiological responses to the situation (e.g., to stress or novelty). Here, what previously seemed to be a convergence of response for males ad females becomes a divergence due to different responses to the situation by males and females. In both cases the sex differences are derived from differences in the underlying processes mediating the responses of males and females.

4) Population Differences. Finally, there may be population sex differences where there are two (or more) phenotypes that are differentially represented among males and females. These population differences are not necessarily caused through the processes of sexual differentiation, but may interact with sexual differentiation and so result in different proportions among males and females.

Multiple types of sex differences can be present in an individual and contribute to a given trait. In the case of addiction, for example, there are both quantitative differences and population differences that contribute (Becker and Koob, 2015; Hu et al., 2004; Thomas et al., 2009). We reiterate again that most of our discussion is from a heterosexual/cisgender perspective and there are also lesbian, gay, bisexual, transsexual and intersex perspectives that may be affecting the expression of traits in humans. Very little research has examined addiction among 
these groups other than to note that there is increased risk for addiction among gays and lesbians (Gruskin et al., 2008; Sandfort et al., 2014).

Given how easily scientific findings can be misinterpreted or over-simplified, with important social and political consequences, we all have a stake in ensuring that a central message of neuroscience today, that our brains are "plastic" and they are constantly changing, is heard as we are talking about sex differences. As scientists it is important to present our findings in a way that makes this clear to the public when our latest research results are disseminated and used to inform policy and political debates.

\section{Environmental Influences, Historical Perspectives and New Questions. This} message of plasticity and interaction between an individual and the setting is important, because for humans and other animals, the use of drugs and the changes that occur in the brain as a result of their use, are strongly influenced by the environment in which drug taking occurs (Crombag et al., 2001; Ferguson and Robinson, 2004; Uslaner et al., 2001). In humans, cultural customs shape what drugs we take and how we use them, with significant differences also seen within a given cultural or social group where patterns of use frequently differ by age, gender, status, class position, ethnic and racial variations, and other factors. Even the point at which drug use is seen as a problem, as opposed to an acceptable, or even celebrated behavior, can vary widely across time and place and by gender (Courtright, 2009)

Across many historical periods and cultural settings, however, some consistent patterns emerge related to sex differences. The use of substances for recreation and pleasure has generally been more acceptable for men than for women, while women may be more likely to be medicated for their problems (Kandall, 1999). Accordingly, a harsher standard of judgment, including informal social sanctions and even punishment, is often brought to bear against those

This article is protected by copyright. All rights reserved. 
women who do use mind-altering substances for fun or on their own initiative. Some scientists, physicians, mental health professionals, and epidemiologists have argued that the greater constraints on women's drug-taking in many societies have had a protective effect against the development of addiction in women. As some of these strictures have relaxed in the modern United States, many of these same experts warn that women may be "closing the gap" with men's rates of use (CASA, 2006).

Consumption is related to access, a relationship most societies recognize and try to control by setting rules for who may use psychoactive substances and under what circumstances. Some evidence suggests that women may be more sensitive than men to these social and legal constraints, underscoring the importance of studying sex differences in context in the development of addiction. For example, the widespread production and consumption of distilled alcohol, gin in particular, came to be seen as a "woman's problem" in eighteenthcentury England: in one year alone (1738), 75\% of the gin-sellers appearing before a magistrate were women. Tighter restrictions and higher taxes on gin reduced use for all, but especially for women (Dillon, 2003)

In the nineteenth-century United States, "patent medicines," a name given to various commercial nostrums that contained alcohol and even opiates, were heavily marketed to women. These drugs were widely available without prescription and they were used to treat a myriad of health conditions. Many women relied on them to treat "female complaints," the pain and discomfort associated with menstruation, childbirth, and menopause (Stage, 1979). In a form of iatrogenic addiction, where sanctioned medical use leads to dependence, more women than men were addicted to opiates (opium, morphine, laudanum or heroin) with estimates indicating that $66 \%$ to $80 \%$ of the opium users were women during the late 1800 's (Kandall, 
1999). One physician insisted at the time that, "women were more prone to opium addiction because of their 'more nervous organization and tendency to hysterical and chronic diseases'" (Hamlin, 1882, as cited in Kandall 1999, p.29).

Important new laws in the early-twentieth-century United States profoundly altered access to drugs. The Pure Food and Drug Act of 1906 (United States Statutes at Large (59th Cong., Sess. I, Chp. 3915, p. 768-772)) required new systems of drug approval and labeling and created the Food and Drug Administration. In 1914, the Harrison Tax Act drastically reduced the availability of narcotics by imposing a prohibitive tax and restricting the ability of physicians to "maintain" their addicted patients. These laws together rendered the patent medicine business much less lucrative and limited the market for commercial nostrums and narcotics (Courtright, 1982a). As a result, the profile of the typical drug user shifted dramatically over the next few decades, from a white woman who started using a patent medicine or narcotic for medicinal reasons, to a man who lived in an urban setting and was increasingly likely to be a member of a racial minority (Courtright, 1982a, 1982b). In fact, the proportion of women narcotic addicts declined to $50 \%$ of the population by 1918 , and the proportion continued to decline until women were approximately $25-30 \%$ of addicts in the USA by the beginning of World War II (CASA, 2006).

During the second half of the twentieth century, new wonder drugs echoed the story of patent medicines, as doctors increasingly prescribed tranquilizers and stimulants to women for mood disorders, weight management, and even a generalized malaise that seemed to affect many affluent housewives (CASA, 2006; Kandall, 1999). By the end of the 1960's two-thirds of the prescriptions for the tranquilizers Valium and Librium were to women (CASA, 2006). This phenomenon came to light in the late 1970s with the "Valium Panic" that depicted the "mother's 
little helpers" as a central symbol of sexism that white, middle-class women required liberation from (Herzberg, 2006).

The drug industry at the time was also promoting the use of amphetamines as appetite suppressants, and women were consuming $80 \%$ of the prescription amphetamines in the USA. Since the 1960's the psychomotor stimulants (amphetamine, methamphetamine, methyphenidate, and cocaine) have been used by women for appetite suppression and as a 'pick-me up'. It is important to note that both of these patterns of use initially stemmed from medical practices: physicians were prescribing the drugs for women to a greater extent than for men (CASA, 2006).

'During the 1980's and 1990's the illicit use of the psychomotor stimulant drugs among individuals under the age of 25 was predominantly by males, but by 2006 slightly more women under 25 were using these drugs than men of the same age, and this pattern persists (Johnston et al., 2008). Since the 1960's the use of all addictive drugs by women has been increasing. It is still the case, that for individuals 18 or older, there are more men than women who are drug addicts. In the 2008 SAMSHA report, among youths aged 12 to 17, however, the rate of substance dependence or abuse among males was similar to the rate among females (8.0 vs. 8.1 percent) (Johnston et al., 2008).

These numbers are only part of the story; they do not explain why rates of use and abuse vary by sex and over time. It may be that women as a group are more sensitive to the availability of drugs than are men, and this needs to be studied more systematically. But we also need to study more proximal factors: where are the drugs taken and what types of events or factors induce use or trigger relapse? Context can affect what drugs are used and context or cues in the environment can trigger relapse. In both humans and laboratory animals cocaine is 
used more frequently outside the home environment while heroin is used more in the home (Badiani, 2013; Badiani and Spagnolo, 2013). Whether there are sex / gender differences in how context affects drug choice and use has not been systematically investigated, but given the historical evidence that women may be affected to a greater extent by availability and social conventions than are men (Van Etten et al., 1999), this should be investigated further and may have important implications for treatment and recovery protocols.

These ideas are supported by evidence that context, such as a supportive social environment, can have beneficial effects on psychiatric disorders, including depression and drug dependence (Glazer et al., 2003; Reinelt et al., 2015). Social support can reduce drug use, decrease stress and increase the effectiveness of treatment (Dluzen and Liu, 2008). As a consequence, behavioral therapy, support groups and community-based programs are usually considered important components of successful treatment of drug dependence.

None of these conditions can be mimicked exactly in preclinical studies of drug abuse, but in laboratory animals, social housing of female rats decreases motivation to take cocaine while not affecting motivation for cocaine in male rats (Westenbroek et al., 2013). In other studies, socially housed males, compared with isolated males, took more amphetamine (Gipson et al., 2011). Interestingly, in a different study, socially housed males were not different from isolated males, in terms of cocaine-self-administration, but when socially housed males could both self-administer cocaine their cocaine intake was greater than for socially housed males when only one male could take cocaine (Smith, 2012). As mentioned previously, males are more likely to relapse in response to drug-associated cues and females are more sensitive to stress in terms of relapse. So considering how the social environment interacts with the cues in 
the physical environment differentially for males and females may be important for treatment and for development of better animal models.

It is not just sex I gender differences. While we might wish that science stands outside popular attitudes about addicts, even a brief consideration of policy debates, funding priorities, and newspaper headlines all demonstrate how entwined science is with cultural values. As scientists, we have the opportunity to use our findings to inform current debates, and in doing so we must be mindful of the ways in which power and stigma influence beliefs about addiction and shape the experiences of addicts.

For one thing, cultural expectations and perceptions about women affect how women who use drugs are perceived in society. Addicted women are often considered to be "doubly" deviant. Their drug use means they have failed to behave as "proper" women who are supposed to be selfless and nurturing above all. But addicted women also do not look like "proper" addicts, since men's patterns of use, routes to treatment, and needs in recovery have defined the standards in all these realms. As a result, even when they seek help, addicted women can be denigrated as more pathological than their male counterparts (Campbell and Ettore, 2011).

Secondly, scientific and popular attention to women's substance use has often been driven by concerns about pregnancy and children-in other words, focused on how women's substance use affects others. Understanding the reproductive implications of substance use is importânt, and addiction profoundly affects family members and friends. Still, these efforts frequently have a subtext of blaming mothers for their children's difficulties and suggest that the women themselves do not deserve care or sympathy. Moral panics over Fetal Alcohol 
Syndrome (FAS) and "crack babies" reinforced the sense that women who drink and use drugs are especially deviant because they have violated their maternal role (Golden, 2005)

Historically, racial biases as well as gender role conventions have regulated who should be allowed to use drugs. The early settlers of colonial New England, who are referred to as the Puritans, consumed a considerable amount of alcohol per capita, much more than would be considered acceptable today. But their drinking was integrated into the rhythm of the day and significant social sanction was brought to bear against intoxication. Even as they enjoyed their hard cider and beer, the early colonists were very concerned with regulating or forbidding consumption by American Indians (Mancall, 1995; Rorabaugh, 1979)

'In more recent times, drug 'epidemics' have also been tied to particular racial and ethnic groups with disproportionate effects on communities of color. An example of this is the crack cocaine epidemic in the USA in the late 1980s to early 1990s, when the penalty for being arrested with a small quantity of crack was substantially greater than the penalty associated with the same quantity of cocaine powder (favored by affluent white people) even though chemically they are the same substance. This disparity had devastating consequences in African-American urban communities and shows how stereotypes about drug users became incorporated into the legal system and only reinforced power differentials in American society (Hart, 2013). The policy response to the "crack epidemic", a reinvigoration of the "War on Drugs," was also very heavy handed toward women and has been renamed by some feminists as the "War against Black Women." Media depictions of the so-called "crack whore," an African-American woman who traded sex for drugs or money to buy drugs, exacerbated the idea that drug-using women are not only bad mothers but sexually promiscuous. In this way, debates about drug use can 
reinforce pejorative beliefs about women overall as well as magnify stereotypes at the intersection of gender and race (Acker, 2002; Campbell, 2000).

All of these attitudes and beliefs shape treatment practices and research priorities. Addiction treatment is stigmatized within the health care professions, and many health care professionals would prefer not to work with addicts (Reyre et al., 2014). In biomedical sciences, females are not studied to the same extent as males in either clinical or preclinical studies (Beery and Zucker, 2011; Clayton and Collins, 2014). Those who study populations who are highly stigmatized can be stigmatized also, (i.e., contagion stigma) within one's discipline and profession. Perhaps women addicts have not been studied more systematically because addicted women are perceived as being doubly stigmatized.

Conclusions and recommendations for future research. There are sex differences in addiction and relapse that can be seen in the human population and in animal models. Among the vulnerable populations, females escalate drug use more rapidly and relapse is more likely to be triggered by stressful or emotional stimuli in women. But sex differences are not solely determined by our biology—-there are also cultural influences that differentially affect men and women and how they respond to drugs of abuse. Going forward, our animal models and the clinical research needs to take into consideration how contextual and social factors may influence the processes of addiction and relapse differentially in males and females.

Addiction is both a cultural and biological phenomena. From the historical record it seems that women may be more likely than men to become addicted when drugs are freely available, and that social / legal constraints have a greater effect on women than on men. These factors need to be studied systematically in a clinical population, and we need animal models for 
these conditions in order to investigate whether there are biological mechanisms mediating the sex differences.

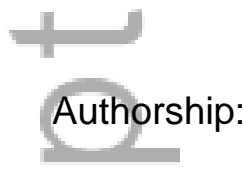

= JBB, MM, and BGR were all involved in the conception of this manuscript. JBB drafted (

the original manuscript. All provided critical revisions of the manuscript for important intellectual content. All authors critically reviewed content and approved final version for publication.

\section{Acknowledgments}

We would like to thank the Institute for Research on Women and Gender, The University of Michigan School of Social Work, the University of Michigan Substance Abuse Research Center (UMSARC), and the Center for Advanced Research and Solutions for Society for their support for the workshops that inspired this article.

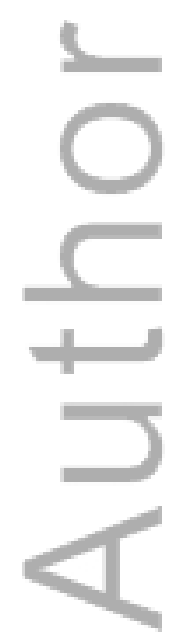




\section{Bibliography}

Acker, C.J. (2002). Creating the American Junkie (Baltimore, MD: Johns Hopkins University Press).

Anker, J.J., and Carroll, M.E. (2010). Reinstatement of cocaine seeking induced by drugs, cues, and stress in adolescent and adult rats. Psychopharmacology (Berl) 208, 211-222.

Badiani, A. (2013). Substance-specific environmental influences on drug use and drug preference in animals and humans. Curr Opin Neurobiol 23, 588-596.

Badiani, A., and Spagnolo, P.A. (2013). Role of environmental factors in cocaine addiction. Curr Pharm Des 19, 6996-7008.

Becker, J.B., and Hu, M. (2008). Sex differences in drug abuse. Front Neuroendocrinol 29, 36-47.

Becker, J.B., and Koob, G.F. (2015). Sex Differences in Animal Models: Focus on Addiction. Pharmacol Rev submitted.

Becker, J.B., Perry, A.N., and Westenbroek, C. (2012). Sex differences in the neural mechanisms mediating addiction: a new synthesis and hypothesis. Biol Sex Differ 3, 14.

Beery, A.K., and Zucker, I. (2011). Sex bias in neuroscience and biomedical research. Neurosci Biobehav Rev 35, $565-572$.

Bem, S. (1994). The Lenses of Gender: Transforming the Debate on Sexual Inequality (New Haven: Yale University Press).

Brady, K.T., and Randall, C.L. (1999). Gender differences in substance use disorders. Psychiatr Clin North Am 22, $241-252$

Cahill, L. (2014). Equal $\neq$ the same: sex differences in the human brain. Cerebrum 2014, 5.

Campbell, N.D. (2000). Using Women: Gender, Drug Policy, and Social Justice (New York: Routledge).

Campbell, N., and Ettore, E. (2011). Gendering Addiction: The Politics of Drug Treatment in a Neurochemical World (New York: Palgrave Macmillan).

CASA (2006). Women under the Influence (Baltimore: The Johns Hopkins University Press).

Clark, A.E. (1990). Women's Health: Life-Cycle Issues (New York: Garland Publishers).

Clayton, J.A., and Collins, F.S. (2014). Policy: NIH to balance sex in cell and animal studies. Nature 509, 282-283.

Courtright, D.T. (1982a). Dark Paradise: Opiate Addiction in America before 1940 (Cambridge, MA: Harvard University Press). 
Courtright, D.T. (1982b). The Female Opiate Addict in Nineteenth-Century America. Essays in Arts and Sciences $10,161-171$.

Courtright, D.T. (2009). Forces of Habit: Drugs and the Making of the Modern World (Cambridge, MA: Harvard University Press).

Crombag, H.S., Badiani, A., Chan, J., Dell'Orco, J., Dineen, S.P., and Robinson, T.E. (2001). The ability of environmental context to facilitate psychomotor sensitization to amphetamine can be dissociated from its effect on acute drug responsiveness and on conditioned responding. Neuropsychopharmacology 24, 680-690.

Degler, C. (1991). In Search of Human Nature: The Decline and Revival of Darwinism in American Social Thought (New York: Oxford University Press).

Dillon, P. (2003). The Much Lamented Death of Madame Geneva. The Eighteenth Century Gin Craze (Boston, MA: Justin, Charles \& Co.).

Dluzen, D.E., and Liu, B. (2008). Gender differences in methamphetamine use and responses: a review. Gend Med $5,24-35$.

Fausto-Sterling, A. (2012). Sex/Gender: Biology in a Social World (New York and London: Routledge).

Ferguson, S.M., and Robinson, T.E. (2004). Amphetamine-evoked gene expression in striatopallidal neurons: regulation by corticostriatal afferents and the ERK/MAPK signaling cascade. J Neurochem 91, 337-348.

Fine, C. (2013). Is There Neurosexism in Functional Neuroimaging Investigations of Sex Differences? Neuroethics 6, 369-409.

Gipson, C., Yates, J., Beckmann, J., Marusich, J., Zentall, T., and Bardo, M. (2011). Social facilitation of damphetamine self-administration in rats. Psychopharmacol 18, 409-419.

Glazer, S., Galante, r M., Megwinoff, O., Dermatis, H., and Keller, D. (2003). The role of therapeutic alliance in network therapy: a family and peer support-based treatment for cocaine abuse. Subst Abus 31, 385-398.

Golden, J. (2005). Message in a Bottle: The Making of Fetal Alcohol Syndrome (Cambridge, Mass.: Harvard University Press).

Gruskin, E.P., Byrne, K.M., Altschuler, A., and Dibble, S.L. (2008). Smoking it all away: influences of stress, negative emotions, and stigma on lesbian tobacco use. J LGBT Health Res 4, 167-179.

Hart, C. (2013). High Price (New York: Harper Collins).

Hartwell, E.E., and Ray, L.A. (2013). Sex moderates stress reactivity in heavy drinkers. Addict Behav 38, $2643-$ 2646.

Heffner, J.L., Blom, T.J., and Antheneli, R.M. (2011). Gender differenes in trauma history and symptoms as predictors of relapse to alcohol and drug use. Am J Addict 20, 307=311. 
Herzberg, D.L. (2006). "The Pill You Love Can Turn on You”: Feminism, Tranquilizers, and the Valium Panic of the 1970s. American Quarterly 58, 79-103.

Hu, M., Crombag, H.S., Robinson, T.E., and Becker, J.B. (2004). Biological basis of sex differences in the propensity to self-administer cocaine. Neuropsychopharmacology 29, 81-85.

Hyman, S.M., Paliwal, P., Chaplin, T.M., Mazure, C.M., Rounsaville, B.J., and Sinha, R. (2008). Severity of childhood trauma is predictive of cocaine relapse outcomes in women but not men. Drug Alcohol Depend 92, 208216.

Joel, D., Berman, Z., Tavor, I., Wexler, N., Gaber, O., Stein, Y., Shefi, N., Pool, J., Urchs, S., Margulies, D.S., et al. (2015). Sex beyond the genitalia: The human brain mosaic. Proc Natl Acad Sci U S A 112, 15468-15473.

Johnston, L.D., O’Malley, P.M., Bachman, J.G., and Schulenberg, J.E. (2008).

Kachadourian, L.K., Pilver, C.E., and Potenza, M.N. (2014). Trauma, PTSD, and binge and hazardous drinking among wömen and men: findings from a national study. J Psychiatr Res 55, 35-43.

Kandall, S.R. (1999). Substance and Shadow: Women and Addiction in the United States (Cambridge, MA: Harvard University Press).

Kevles, D. (1985). In the Name of Eugenics: Genetics and the Uses of Human Heredity (Cambridge, MA: Harvard University Press).

Lorber, J. (1994). Paradoxes of Gender (New Haven: Yale University Press).

Lorber, J. (2005). Breaking the Bowls: Degendering and Feminist Change (New York: W.W. Norton).

Mancall, P. (1995). Deadly Medicine: Indians and Alcohol in Early America (Ithaca: Cornell University Press).

McCarthy, M.M., Arnold, A.P., Ball, G.F., Blaustein, J.D., and De Vries, G.J. (2012). Sex differences in the brain: the not so inconvenient truth. J Neurosci 32, 2241-2247.

Petersen, J., and Hyde, J.S. (2014). Gender-related academic and occupational intersts and goals. In The Role of Gender in Educational Contexts and Outcomes, L.S. Liben, and R.S. Bigler, eds. (New York: Elsevier),.

Reinelt, E., Barnow, S., Stopsack, M., Aldinger, M., Schmidt, C.O., John, U., and Grabe, H.J. (2015). Social support and the serotonin transporter genotype (5-HTTLPR) moderate levels of resilience, sense of coherence, and depression. Am J Med Genet B Neuropsychiatr Genet 168B, 383-391.

Reyre, A., Jeannin, R., Larguèche, M., Hirsch, E., Baubet, T., Moro, M.R., and Taïeb, O. (2014). Care and prejudice: moving beyond mistrust in the care relationship with addicted patients. Med Health Care Philos 17, 183190.

Rorabaugh, W.J. (1979). The Alcoholic Republic: An American Tradition (Now York and Oxford: Oxford Universityy Press). 
Sanchis-Segura, C.S., and Becker, J.B. (2016). Why we should consider sex (and study sex differences) in addiction research. Addict Biol submitted.

Sandfort, T.G., de Graaf, R., Ten Have, M., Ransome, Y., and Schnabel, P. (2014). Same-sex sexuality and psychiatric disorders in the second Netherlands Mental Health Survey and Incidence Study (NEMESIS-2). LGBT Health 1, 292-301.

Smith, M.A. (2012). Peer influences on drug self-administration: social facilitation and social inhibition of cocaine intake in male rats. Psychopharmacology (Berl) 224, 81-90.

Stage, S. (1979). Female Complaints: Lydia Pinkham and the Business of Women's Medicine (New York: Norton).

Thomas, M.B., Hu, M., Lee, T.M., Bhatnagar, S., and Becker, J.B. (2009). Sex-specific susceptibility to cocaine in rats with a history of prenatal stress. Physiol Behav 97, 270-277.

Uslaner, J., Badiani, A., Day, H.E., Watson, S.J., Akil, H., and Robinson, T.E. (2001). Environmental context modulates the ability of cocaine and amphetamine to induce c-fos mRNA expression in the neocortex, caudate nucleus, and nucleus accumbens. Brain Res 920, 106-116.

Van Etten, M.L., Neumark, Y.D., and Anthony, J.C. (1999). Male-female differences in the earliest stages of drug involvement. Addiction 94, 1413-1419.

Walitzer, K.S., and Dearing, R.L. (2006). Gender differences in alcohol and substance use relapse. Clin Psychol Rev $26,128-148$.

Westenbroek, C., Perry, A.N., and Becker, J.B. (2013). Pair housing differentially affects motivation to selfadminister cocaine in male and female rats. Behav Brain Res 252, 68-71.

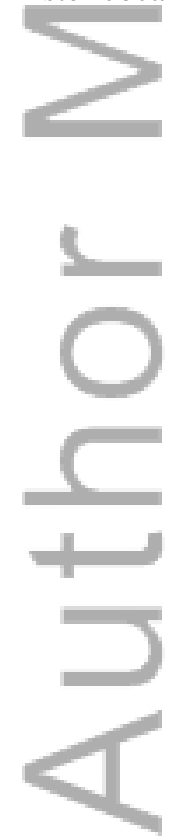

